\title{
Patient complaints about Canadian doctors on the rise
}

Cite as: CMAJ 2018 April 3;190:E408. doi: 10.1503/cmaj.109-5585

Posted on cmajnews.com on Mar.15, 2018.

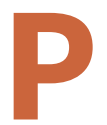

atient complaints against doctors are on the rise, with communication problems at the root of most cases, according to the Canadian Medical Protective Association (CMPA).

Physician requests for CMPA assistance with regulatory college complaints have increased $85 \%$ over the past decade. The medicolegal protective agency received 3387 requests from members in 2016, up from 1983 in 2007. Most cases came from Ontario; however, "there seems to be a rise across the board," says Dr. Todd Watkins, managing director of physician services at the CMPA. "The rising numbers are really a symptom of a system and profession under stress, and patients who are unhappy with the care they're being provided." Communication was a key issue in most cases. For example, patients said their physicians were rude, used a condescending tone, or dismissed their concerns. In other cases, regulators found that patients didn't understand or receive necessary information about treatments.

Increasing system pressures are contributing to communication breakdown, Watkins says. "Time is certainly an issue, and technology is an issue." Electronic health records, in particular, "can be seen as depersonalizing that interaction." Burnout and compassion fatigue also make it difficult for physicians to "maintain time and patience with their patients."

Meanwhile, patients' expectations of physicians are increasing, Watkins adds.

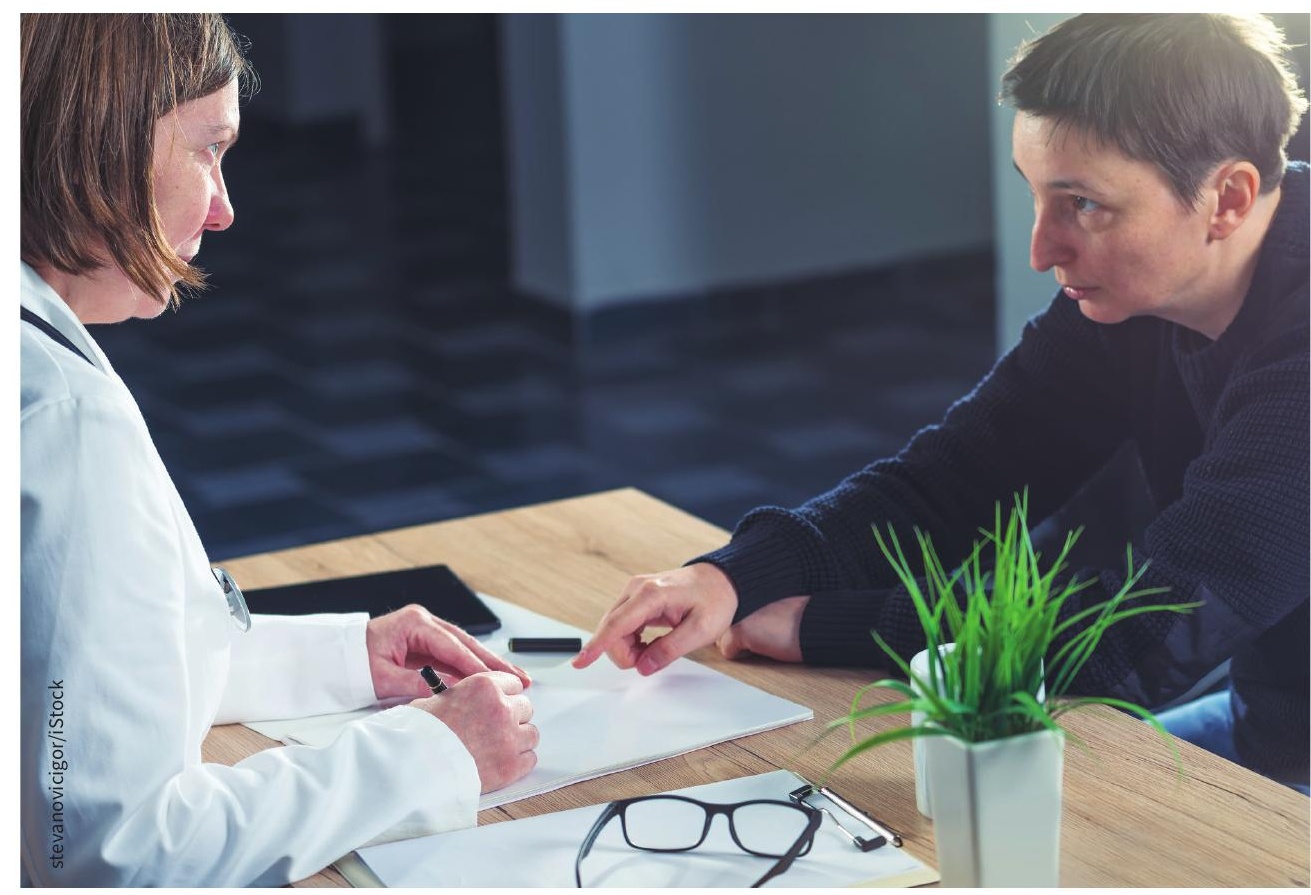

The Canadian Medical Protective Association has seen a major uptick in physicians seeking assistance with regulatory college complaints over the past decade.

"Patients are much more willing to speak out about the services and professionalism they're experiencing." In some cases, doctors become a lightning rod for patients' frustrations with the system as a whole, he says. "The physician is often the one at the frontline and the face of a failing system."

According to the CMPA, many physicians are unaware of their communication skill level, "in some instances overestimating it."

The association recommends that physicians improve their communication skills by focusing on patients as individthy and sharing decision-making. This includes simple steps like greeting patients and allowing them to share their stories uninterrupted. According to the CMPA, research shows that most patients finish what they want to say in 30 seconds to two minutes.

"It's about the patient feeling like they've been heard," Watkins says. "It's as simple as that."

\section{Lauren Vogel, CMAJ} uals, listening actively, expressing empa- 